AGRICULTURAL EXPERIMENT STATION

F. B. Mumford, Director

\title{
Colloidal Properties of Soil Organic Matter
}

L. D. Baver and Nathan S. Hall

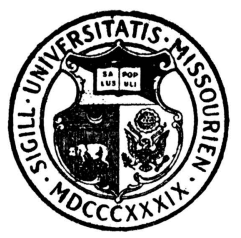

COLUMBIA, MISSOURI 


\section{TABLE OF CONTENTS}

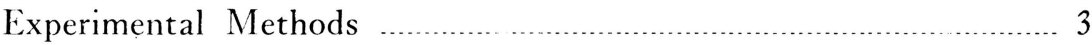

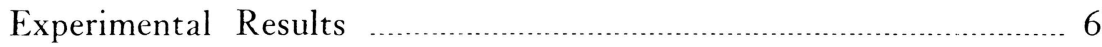

Specific conductivity and migration velocities ……................ 6

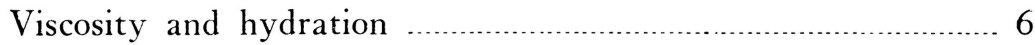

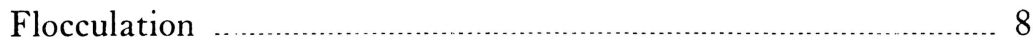

Releàse and adsorption of exchangeable cations _.......................12

Reversibility …….............. 14

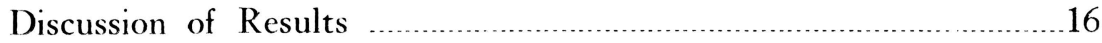

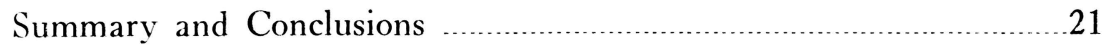

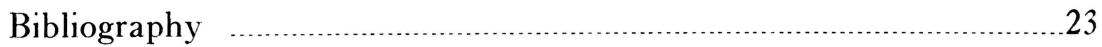




\title{
Colloidal Properties of Soil Organic Matter
}

\author{
L. D. Baver and Nathan S. Hall
}

The role of organic matter in the various physico-chemical phenomena observed in soils has long been recognized by investigators in this country and in Europe. The study of the humus fraction of the soil, however, has been very limited since the classical work of Oden ${ }^{12}$.*

Baver $^{1}$ found that the cation adsorption capacity of soils due to organic matter varied from 30 to $60 \%$. Hissink ${ }^{8}$, observed that the equivalent weight of humus, i. e. mgms. humus per m. e. cation adsorbed, from 15 soils averaged 176 as compared to 1225 for clays. McGeorge $^{11}$, studying the ligno-humate fraction of 10 soils, found the exchange capacity to be 321 to 431 m.e. per 100 grams of colloid. This gives an equivalent weight of 312 to 232 for the humus substance. Powers ${ }^{13}$, using the colloids dispersible with $\mathrm{Na}_{2} \mathrm{C}_{2} \mathrm{O}_{4}$ from peats, found the exchange capacity ranged from 86 to 122 m.e. base per 100 grams colloid. He found a high correlation between the ash content and the exchange capacity of the colloids.

Although there has been considerable work on the base exchange properties of soil organic matter, there are insufficient data characterizing the colloidal nature of humus. It is the purpose of this paper to report the results of studies of such colloidal properties of soil organic matter as exchange reactions, charge, flocculation and hydration.

\section{EXPERIMENTAL METHODS}

The colloid used was extracted from peat by the method of Waks$\operatorname{man}^{16}$ for $\propto$-humus. It was electrodialyzed until free of chlorides and then thoroughly dispersed. At no time were the systems allowed to become dry.

The exchange capacity of the colloid was determined (1) conductometrically and potentiometrically using the aeration method of Bradfield and Allison ${ }^{5}$, and (2) by direct conductometric titrations with $\mathrm{Ca}(\mathrm{OH})_{2}, \mathrm{Ba}(\mathrm{OH})_{2}$, and $\mathrm{Ba}(\mathrm{OH})_{2}$ in the presence of $\mathrm{BaCl}_{2}$. These various methods gave exchange capacities of 385,405 , 408, and 413 m.e. per 100 gms. of colloid, respectively; the average was 403 m.e. base per 100 gms. of colloid for a 0.22 per cent by weight sol. The various standard systems were made up by adding the hydrate of the cation and diluting to a 0.42 per cent sol.

*Superscript numerals refer to "Bibliography," page 23. 
Specific conductivity and migration velocity measurements were made at room temperature, $25^{\circ} \mathrm{C}$., with a 0.42 per cent sol. Migration velocity measurements were determined with the U-tube method used by Bradfield ${ }^{4}$. The liquid above the menisci was adjusted to the same specific conductivity as the sols investigated.

Viscosity measurements were made with 0.42 per cent sols using an Ostwald viscosimeter in a constant temperature bath.

In determining the degree of flocculation it was found best to oxidize the organic matter remaining in suspension with $\mathrm{KMnO}_{4}$ in a hot solution containing $\mathrm{H}_{2} \mathrm{SO}_{4}$. This method was found to give results that could be duplicated and was fairly rapid. In studying the effect of electrolytes on flocculation, $2.0 \mathrm{ml}$. of 0.42 per cent sol were added to a $15 \mathrm{ml}$. centrifuge tube. The cations were added in various symmetry* concentrations as chlorides, except in the case of La which was added as $\mathrm{La}\left(\mathrm{NO}_{3}\right)_{3}$, and the whole diluted to $3.0 \mathrm{ml}$. The systems were allowed to stand for 18 to 24 hours and then were centrifuged at 2000 r.p.m. for 30 minutes. A $1.0 \mathrm{ml}$. aliquot was titrated hot with $\mathrm{KMnO}_{4}$ in the presence of $\mathrm{H}_{2} \mathrm{SO}_{4}$. As a standard, $2.0 \mathrm{ml}$. of $\mathrm{Na}$--humus ( 0.42 per cent by weight) were diluted to $3.0 \mathrm{ml}$. and a $1.0 \mathrm{ml}$. aliquot titrated. A permanent coloration lasting 10 seconds was taken as the end point. Due to the small amount of suspended material, the accuracy of this method is limited. In this investigation, one drop of $\mathrm{KMnO}_{4}$ was equal to 3 per cent suspended material. If a less concentrated solution of $\mathrm{KMnO}_{4}$ is used, the end point is more difficult to determine. The results are expressed as the percentage of humus flocculated.

Flocculation due to the dehydration of the colloid was determined with methyl alcohol rather than absolute ethyl, as the former was found to be more energetic in its dehydration effects. The systems were centrifuged as previously described and a $2.0 \mathrm{ml}$. aliquot titrated hot with acid $\mathrm{KMnO}_{4}$, after boiling off the alcohol. The titer of a blank was less than one drop of $\mathrm{KMnO}_{4}$.

Symmetry values were used to express the energy of adsorption and release of the different cations. To determine symmetry values the amount of cation added was made equal to the exchange capacity of the system. + The released or adsorbed cation is expressed as the

\footnotetext{
* The term symmetry as used in this paper denotes that the milliequivalents of cation added are equal to the exchange capacity of the humus present.

$\dagger$ The cations were added as the chlorides except $\mathrm{La}$ which was added as $\mathrm{La}\left(\mathrm{NO}_{3}\right)_{3}$.
} 
percentage of the total present. To illustrate: 0.1008 m.e. $\mathrm{NaCl}$ were added to $2.0 \mathrm{ml}$. of 0.42 per cent $\mathrm{H}$-humus sol having 0.1008 m.e. exchangeable $\mathrm{H}$ ions present. It was found that 0.0114 m.e. $\mathrm{H}$ ions were released or 0.0114 m.e. $\mathrm{Na}$ adsorbed. The symmetry value is then equal to $0.0114 / 0.1008 \times 100$ or 11.3 per cent. With such systems as Ba- and Ca-humus plus $\mathrm{HCl}$ and $\mathrm{H}$-humus plus $\mathrm{BaCl}_{2}, \mathrm{CaCl}_{2}$ and $\mathrm{La}\left(\mathrm{NO}_{3}\right)_{3}$ that are more than 95 per cent flocculated, it was possible to titrate the acid directly, using phenolphthalein as an indicator. With systems in which the amount of non-flocculated humus was greater than 10 per cent, the end point was difficult to see, and an error was introduced due to the acid humus in suspension.

Preliminary experiments indicated that the released as well as the non-adsorbed $\mathrm{H}$ could be determined conductometrically. A distinct end point is obtained due to the change in conductivity as the $\mathrm{H}$ ions in solution are neutralized. During the neutralization of the adsorbed $\mathrm{H}$ ions the conductivity remains constant in the case of divalent cations and increases slightly in systems of monovalent cations. This technique is essentially the same as that used by Scheele and Row $^{15}$. In order to repress the ionization of the salt formed and to avoid any replacement due to differences in the ions, the systems were titrated with the hydrate of the cation involved or one similar in properties. The results of the symmetry values obtained by conductivity and direct titration methods for the flocculated systems are shown in Table 1.

Table I.-Comparison of Direct and Conductometric Titration of Free H Ions in Colloidal Humus Systems.

\begin{tabular}{|c|c|c|}
\hline & Symmetry & Values \\
\hline System & $\underset{\text { titration }}{\text { Direct }}$ & $\begin{array}{l}\text { Conducto- } \\
\text { metric } \\
\text { titration }\end{array}$ \\
\hline 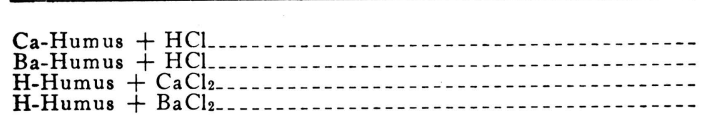 & $\begin{array}{l}\% \\
73.9 \\
77.4 \\
21.2 \\
20.4\end{array}$ & $\begin{array}{l}\% \\
76.0 \\
80.4 \\
22.1 \\
23.6\end{array}$ \\
\hline
\end{tabular}

Because of the hydrolysis of $\mathrm{La}\left(\mathrm{NO}_{3}\right)_{3}$ and $\mathrm{ThCl}_{4}$ it was found advisable to determine the released $\mathrm{H}$ by direct titration. La caused complete flocculation and required no preliminary treatment; in the $\mathrm{H}$-humus plus $\mathrm{ThCl}_{4}$ system the suspended humus had to be flocculated before the titration was performed. In both cases a blank was deterby dehydration with methyl alcohol, fltered, and the alcohol boiled off 
mined. Experiments with completely flocculated systems showed that the alcohol treatment had no significant effect upon the release or adsorption of cations.

The reversibility of dried humates was determined by drying 2.0 $\mathrm{ml}$. of 0.40 per cent sol in an oven at $105^{\circ} \mathrm{C}$., then adding $3.0 \mathrm{ml}$. water and shaking 10 times. At 24 hours intervals a sample was shaken 10 times and centrifuged as in flocculation determinations and a $2.0 \mathrm{ml}$. aliquot titrated with acid $\mathrm{KMnO}_{4}$. The results are expressed as percentage of humus resuspended.

\section{EXPERIMENTAL RESULTS}

\section{Specific Conductivity and Migration Velocities}

The order of specific conductivity of the different colloidal humates was found to be $\mathrm{K}>\mathrm{Na}>\mathrm{Li}>\mathrm{Ca}>\mathrm{Ba}>\mathrm{H}$ (Table 2). McGeorge ${ }^{11}$ observed that the order of specific conductivity of ligno-humates systems was $\mathrm{K}>\mathrm{Na}>\mathrm{H}>\mathrm{Ca}>\mathrm{Ba}$ and that the order of magnitude was $10^{-4}$ mhos. With the exception of the $\mathrm{H}$-system, the order and magnitude of his results agree with those obtained during this investigation. The variation in the order of the $\mathrm{H}$-system might easily be due to differences in the method of removing excess chlorides from the system (washing versus electrodialysis).

The order of the migration velocities was $\mathrm{Li}=\mathrm{Na}>\mathrm{K}>\mathrm{H}>\mathrm{Ca}>\mathrm{Ba}$. This order, with the exception that Li-clay had a higher charge than $\mathrm{Na}$-clay, is the same as was found for Putnam clay ${ }^{2}$. Difficulty was experienced in obtaining a true reading in the anode arm of the U-tube due to a decided fractionation of the system during the experiment into layers. This fractionation was most extreme with the monovalent systems in which case the reading of but one arm was possible. The results reported are for the downward movement of the colloid in the cathode arm and are given in Table 2.

Table 2.-Specific Conductivity and Migration Velocity of Colloidal Humus SYSTEMS.

\begin{tabular}{|c|c|c|c|}
\hline \multirow{3}{*}{ Humus System } & \multicolumn{2}{|c|}{ Specific Conductivity } & \multirow{2}{*}{$\begin{array}{l}\text { Migration } \\
\text { velocity per } \\
\text { unit voltage } \\
\text { gradient } \\
\end{array}$} \\
\hline & Humus & $\begin{array}{l}\text { Ligno- } \\
\text { Humate* }\end{array}$ & \\
\hline & $10-4$ mhos & $10-4$ mhos & $10-6 \mathrm{~cm} / \mathrm{sec} / \mathrm{volt}$ \\
\hline 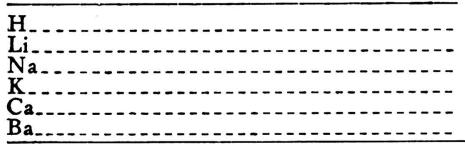 & $\begin{array}{r}2.35 \\
8.14 \\
10.74 \\
17.33 \\
3.19 \\
3.14 \\
\end{array}$ & $\begin{array}{r}3.0 \\
-8.0 \\
11.0 \\
2.5 \\
2.0 \\
\end{array}$ & $\begin{aligned} & 10.4 \\
& 14.2 \\
& 14.2 \\
& 13.3 \\
& 6.6 \\
& 4.4 \\
&\end{aligned}$ \\
\hline
\end{tabular}

*Estimated from McGeorge, Fig. 6, page 230. 


\section{Viscosity and Hydration}

Bontarie and Thevenet ${ }^{3}$ found that the relative viscosity of a 0.567 per cent humus sol was 1.196 as compared to 1.103 that was found in this investigation for a 0.42 per cent sol. The variation might well be due to differences in the exact nature of the humus and in the concentration. They observed that the relative viscosity increased nearly linearly with concentration. The density of the two systems was also different; their humus had a density of 1.176 in dry state as compared to 1.564 determined by the picnometer method on a 0.89 per cent sol.

The results showing viscosity as a function of the adsorbed cation are plotted in Figure 1. It will be noticed that at symmetry concentration, i. e. 400 m.e. base per 100 grams colloid, the monovalent systems have a higher viscosity than at 0.75 or 1.25 times the symmetry concentrations. The order of decreasing viscosity is $\mathrm{Ba}>\mathrm{Ca}>\mathrm{H}>\mathrm{Na}>$ $\mathrm{Li}>\mathrm{K}$.

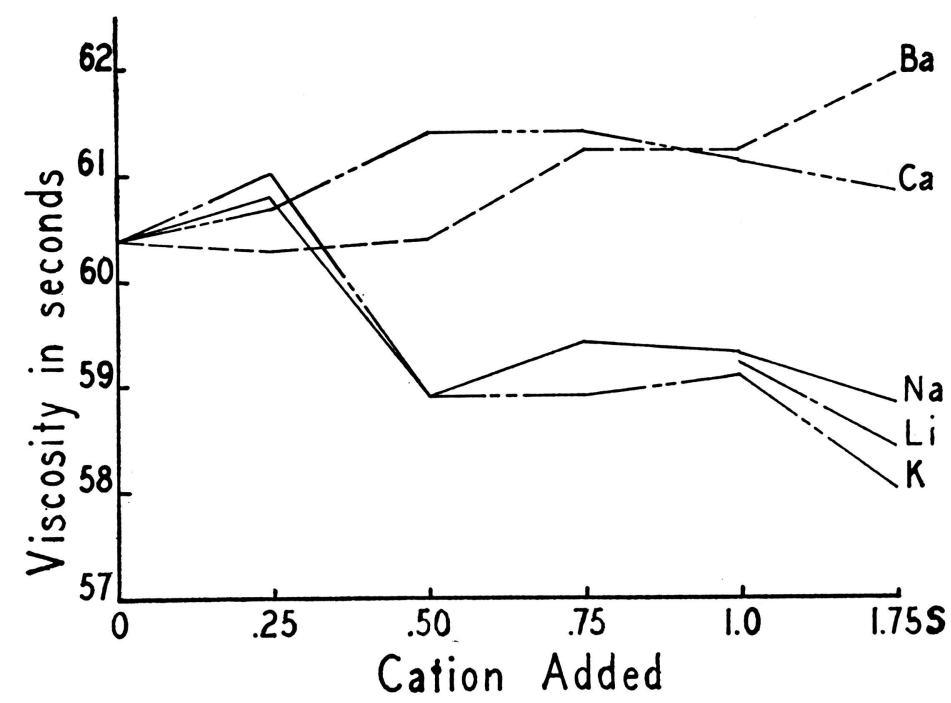

Fig. 1.-Viscosity of colloidal humus systems as a function of the added cation ( $\mathrm{S}=$ symmetry concentration).

In the divalent humates with concentrations greater than symmetry, the increased viscosity is due to the increased flocculation which results in a larger amount of occluded water. The larger floccule that is formed increases the viscosity because of a greater active volume. The decrease in viscosity of monovalent systems at concentrations greater than symmetry is due to the repression of the ionization of the salt and a subsequent decrease in the water hull. At concentrations less than 
symmetry, the water hull has not reached its maximum volume. Baver $^{2}$ noted this same phenomenon with colloidal clay containing mono- and divalent cations in various concentrations. He found that the addition of a monovalent cation in concentration more than 3 symmetry caused an increase in viscosity due to slow coagulation of the clay salt. It was found that with the monovalent humus systems, concentrations of $\mathrm{LiCl}, \mathrm{NaCl}$, and $\mathrm{KCl}$ up to 6 symmetry caused no measurable flocculation in 48 hours.

Calculations of the hydration of humates from viscosity determinations by the Mark and Meyer equations $\left(\mathrm{Lutz}^{10}\right)$ showed that the order of increasing hydration is $\mathrm{Ba}>\mathrm{Ca}>\mathrm{H}>\mathrm{Li}>\mathrm{Na}>\mathrm{B}$. The calculated hydration is expressed as cc. of water per gram of colloid and in the flocculated systems is a measure of the occluded water.

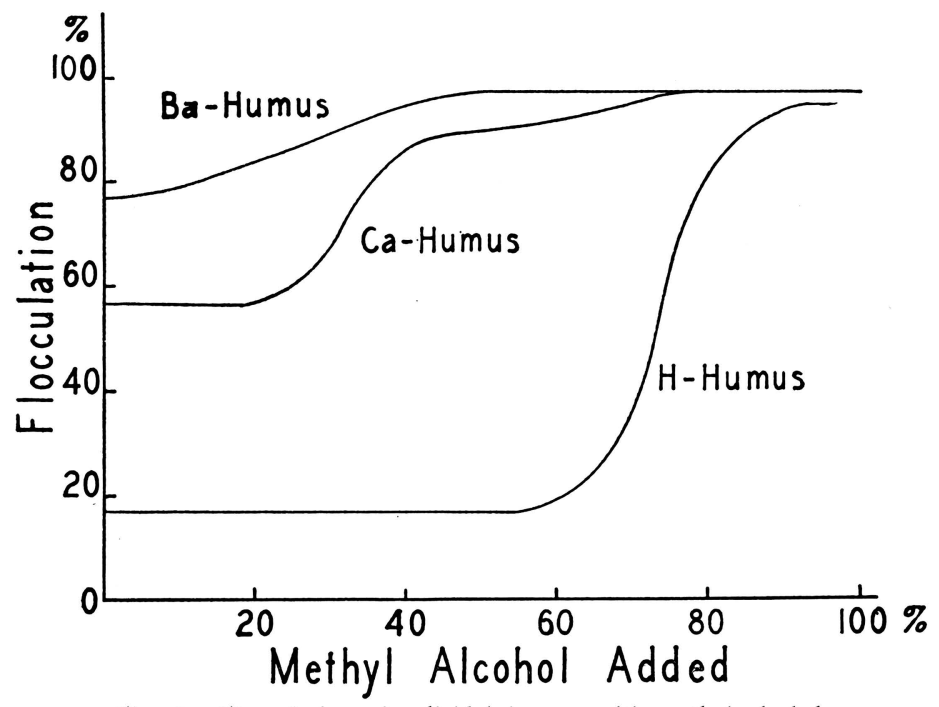

Fig. 2.-Flocculation of colloidal humus with methyl alcohol.

Flocculation results due to the dehydration effect of methyl alcohol are shown in Figure 2. It was found impossible to flocculate the monovalent systems with alcohol at the concentrations used. The results indicate that the order of hydration is $\mathrm{Li}=\mathrm{Na}=\mathrm{K}>\mathrm{H}>\mathrm{Ca}>\mathrm{Ba}$. By comparing this order of hydration with the calculated hydrations it is seen that Ba-humus is highly flocculated and the floccules have a large volume due to the occluded water. However, this water is not tightly held and can be removed by small amounts of alcohol. The amount of alcohol necessary to remove the occluded water increases in the order $\mathrm{Ba}<\mathrm{Ca}<\mathrm{H}$. 


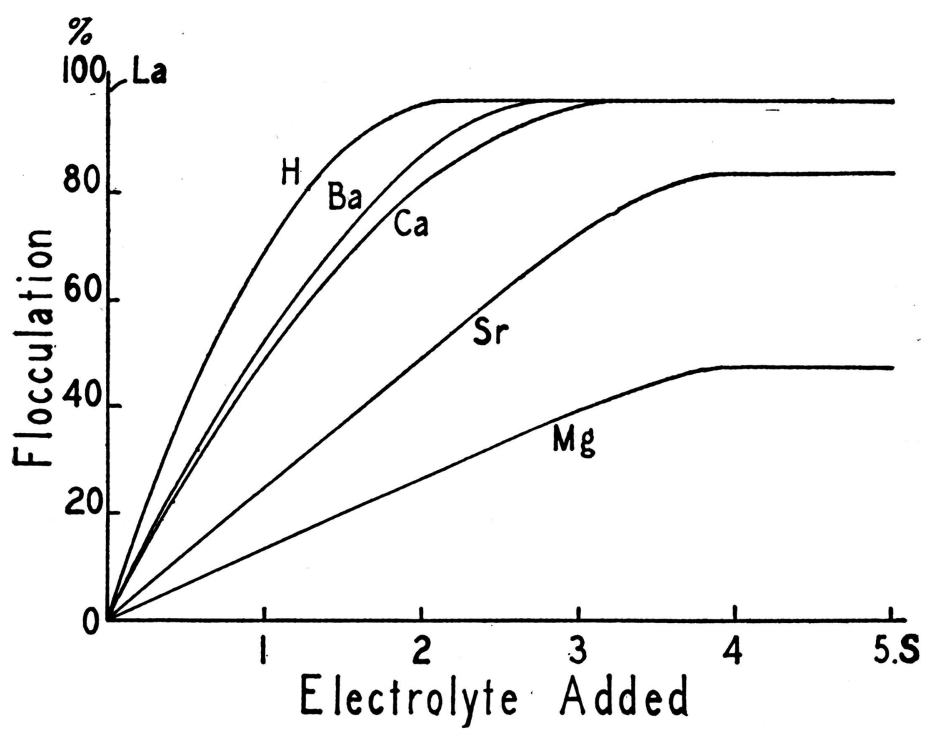

Fig. 3.-Flocculation of Li-humus with various cations.

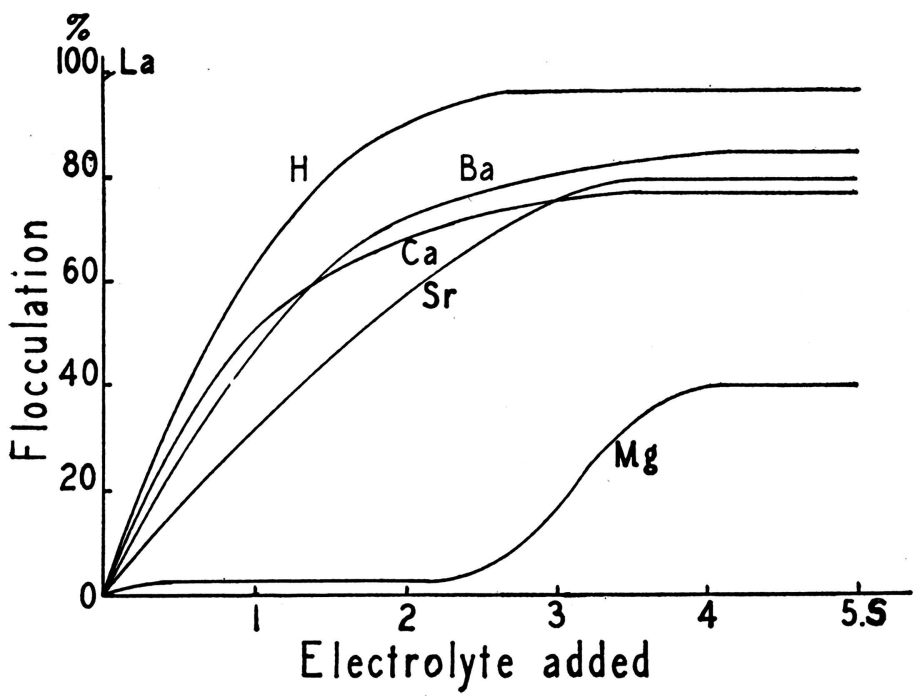

Fig. 4.-Flocculation of Na-humus with various cations.

\section{Flocculation}

The effect of adding electrolytes on the stability of various humus systems is shown in Figures 3 to 9. A summarization of the flocculating effect of electrolytes at different symmetry concentrations is expressed in Table 3. It will be noticed that in the case of monovalent ions, $\mathrm{K}$ is the only one that has an appreciable effect on the flocculation of the 


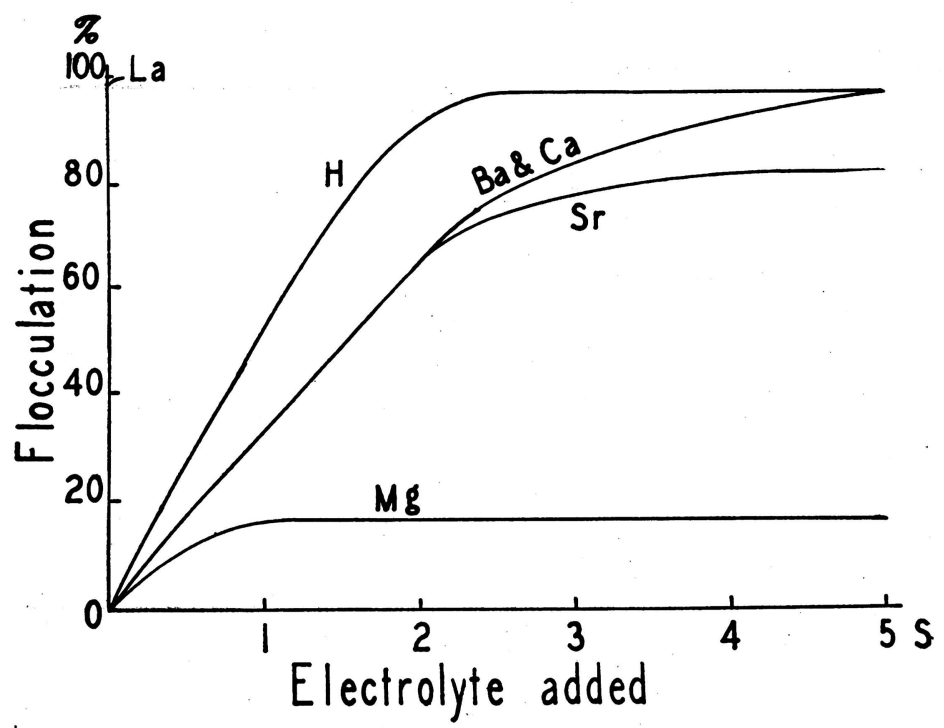

Fig. 5.-Flocculation of K-humus with various cations.

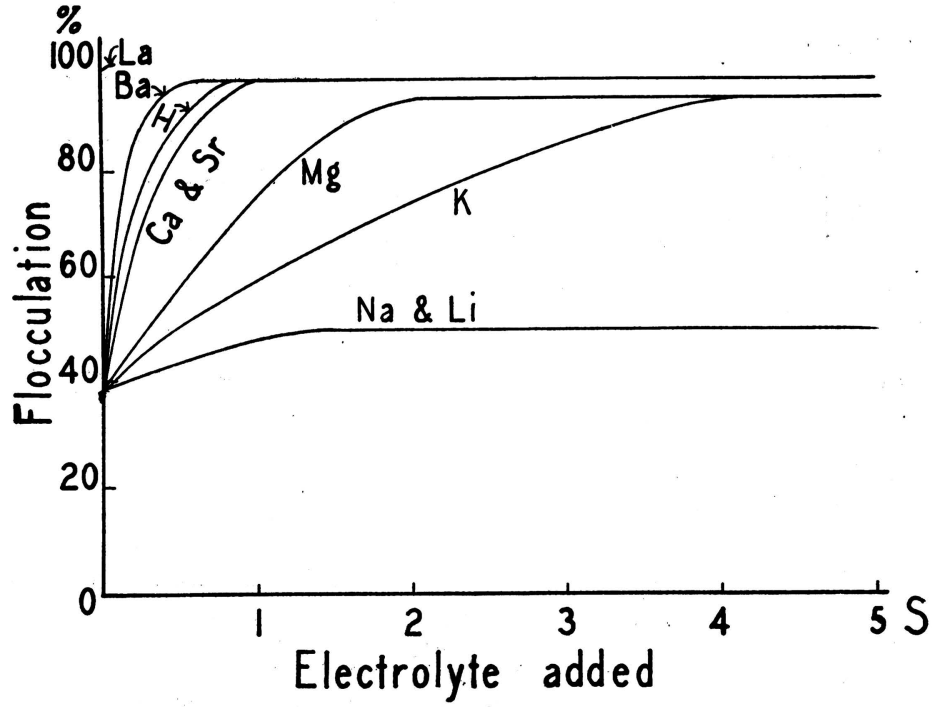

Fig. 6.-Flocculation of $\mathrm{H}$-humus with various cations.

humus systems and then only at higher concentrations in the case of the H-system. This may be explained by the reduction of the charge to the critical potential as will be shown later. The $\mathrm{Mg}$ ion is not as effective in causing flocculation as the other divalent cations. It acts in all cases more like a monovalent ion. It is to be regretted at this time that a $\mathrm{Mg}$-humus system was not prepared in this study due to 


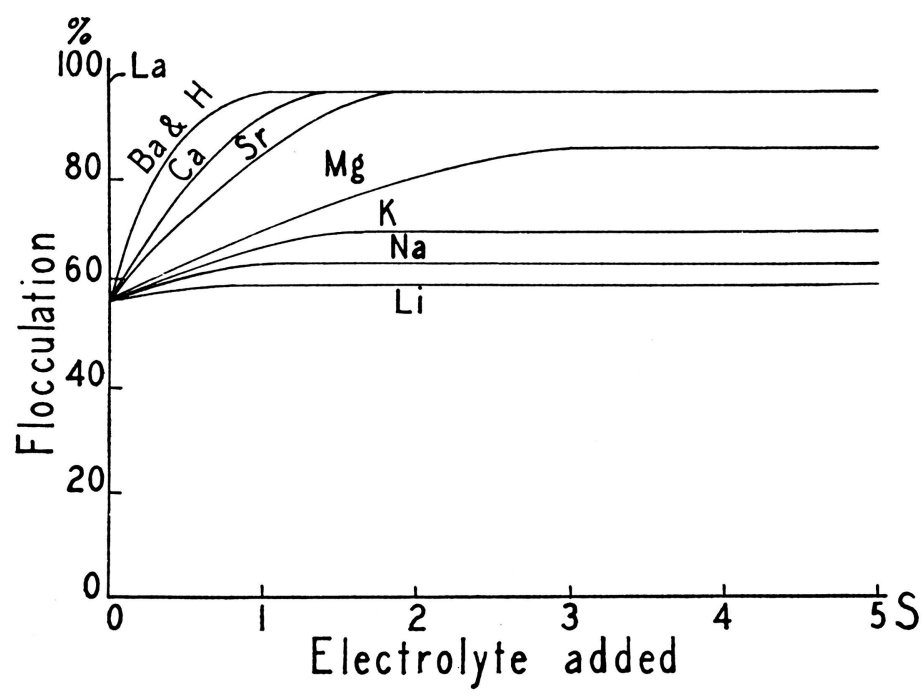

Fig. 7.--Flocculation of Ca-humus with various cations.

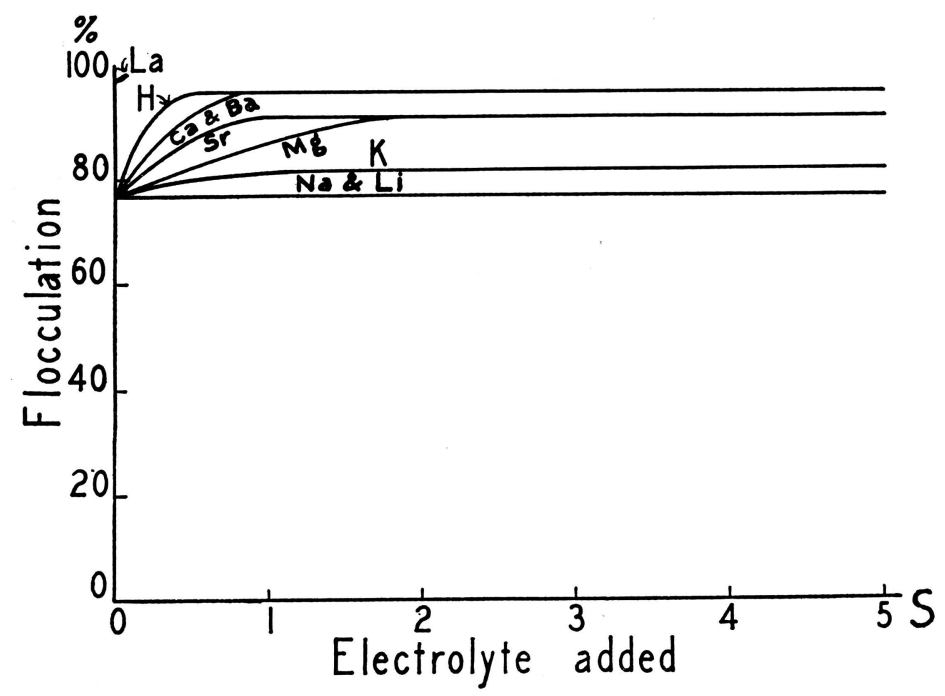

Fig. 8.-Flocculation of Ba-humus with various cations.

the time factor involved in obtaining complete equilibrium between the insoluble $\mathrm{MgO}$ and the acid humus. Of interest, too, is the consistency with which $\mathrm{Sr}$ is out of order in causing flocculation. On the basis of ionic size it should fall between $\mathrm{Ba}$ and $\mathrm{Ca}$. It is seen in Table 3 and Figures 3 to 9 that the largest difference between the flocculat- 
Table 3.-Flocculating Effect of Cations on iColloidal Humus Systems.

\begin{tabular}{|c|c|}
\hline Symmetry concentration* & Order of decreasing effectiveness \\
\hline 0.5 & $\mathrm{La}>\mathrm{H}>\mathrm{Ba}>\mathrm{Ca}>\mathrm{Sr}>\mathrm{Mg}>\mathrm{K}>\mathrm{Na}=\mathrm{Li}$ \\
\hline $1.0 \ldots$ & $\mathrm{La}>\mathrm{H}=\mathrm{Ba}=\mathrm{Ca}>\mathrm{Sr}>\mathrm{Mg}>\mathrm{K}>\mathrm{Na}=\mathrm{Li}$ \\
\hline $2.0 \ldots$ & $\mathrm{La}>\mathrm{H}=\mathrm{Ba}=\mathrm{Ca}=\mathrm{Pr}>\mathrm{Mg}>\mathrm{K}>\mathrm{Na}=\mathrm{Li}$ \\
\hline 3.0 & $\mathrm{La}>\mathrm{H}=\mathrm{Ba}=\mathrm{Ca} \stackrel{>}{=} \mathrm{Sr}>\mathrm{Mg}>\mathrm{K}>\mathrm{Na}=\mathrm{Li}$ \\
\hline
\end{tabular}

*1.0 symmetry concentration indicates that the addition of cations in solution has been equal to the exchange capacity of the system, i. e., 400 m.e. base per 100 grams of colloid.

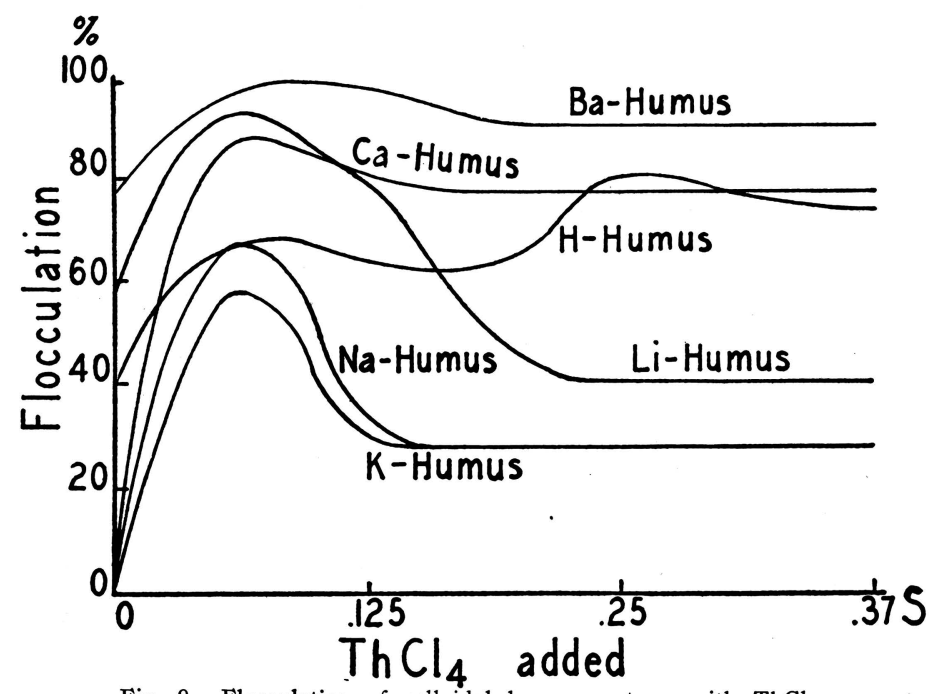

Fig. 9.-Flocculation of colloidal humus systems with $\mathrm{ThCl}_{4}$.

ing effects of $\mathrm{H}, \mathrm{Ca}$ and $\mathrm{Ba}$ ions takes place below symmetry concentration. At higher concentrations there is no significant difference in the flocculating powers of these cations.

\section{Release and Adsorption of Exchangeable Cations}

It is important to know the relative strength of adsorption and releases of the various cations and to compare the values obtained for humus with those already available for clay, bentonite and permutite. The data used for the inorganic systems are those reported by Gieseking and Jenny ${ }^{7}$, and Jenny ${ }^{9}$. These results are given in Table 4. It is unfortunate that sufficient data are not at hand to make a more complete comparison. In colloidal humus systems, the order of adsorption on a $\mathrm{H}$-system, i.e. the replacement of $\mathrm{H}$ from the complex, follows the order of increasing valency. This is in agreement with colloidal 
Table 4.-Adsorption and Release of Cations From Collotdal Humus and Colloidal Alumino-silicates.

\begin{tabular}{|c|c|c|c|c|c|}
\hline \multirow[b]{2}{*}{ System-Added electrolyte } & \multirow{2}{*}{$\begin{array}{c}\text { Ionic } \\
\text { radius } \\
\text { of cation* }\end{array}$} & \multicolumn{2}{|r|}{ Symmetry } & \multicolumn{2}{|l|}{ Values } \\
\hline & & Humus & $\begin{array}{c}\text { Putnam } \\
\text { clay }\end{array}$ & $\begin{array}{c}\text { Bentonite } \\
\text { clayt }\end{array}$ & Permutite $\dagger$ \\
\hline 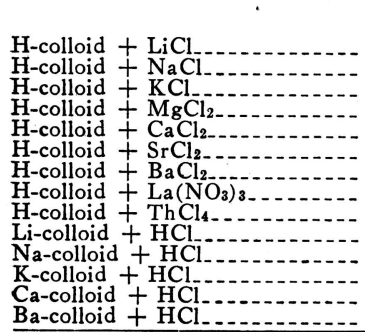 & $\begin{array}{l}\text { A } \\
0.78 \\
0.98 \\
1.33 \\
0.78 \\
1.02 \\
1.28 \\
1.43 \\
1.22 \\
1.10 \\
---- \\
--- \\
--- \\
---\end{array}$ & $\begin{array}{l}\% \\
11.0 \\
11.3 \\
13.3 \\
21.4 \\
22.1 \\
19.0 \\
23.6 \\
65.4 \\
98.2 \\
84.7 \\
79.1 \\
79.4 \\
80.4 \\
76.0\end{array}$ & $\begin{array}{c}\% \\
6.6 \\
6.2 \\
14.5 \\
15.78 \\
34.55 \\
26.89 \\
23.7 \\
-\cdot-- \\
---- \\
--- \\
8 \overline{4} .4 \\
77.8 \\
71.03\end{array}$ & \begin{tabular}{c}
$\%$ \\
18.0 \\
14.6 \\
18.4 \\
---- \\
\hdashline-- \\
\hdashline-- \\
--- \\
--- \\
--- \\
85.45 \\
---- \\
$-\cdots$
\end{tabular} & 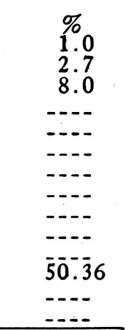 \\
\hline
\end{tabular}

*From Jenny (9).

†From Gieseking and Jenny (7).

alumino-silicates as found by Gieseking and Jenny. The order of magnitude is the same as for Putnam clay with the exception of Sr. The occurrence of $\mathrm{Sr}$ out of its expected order in energy of adsorption is in agreement with the flocculation results. The difference between $\mathrm{Ba}$ and $\mathrm{Ca}$ in energy of adsorption is relatively insignificant, whereas, the energy of release of $\mathrm{Ca}$ with respect to $\mathrm{HCl}$ is significantly greater than that of $\mathrm{Ba}$. This means that while $\mathrm{Ca}$ will be adsorbed on a H-humus to the same extent as $\mathrm{Ba}$, more $\mathrm{Ba}$ will be released from a Ba-humus by $\mathrm{HCl}$ than $\mathrm{Ca}$ from a Ca-humus. The adsorption and release of the monovalent ions studied, with respect to $\mathrm{H}$, are in the expected order. The order of adsorption is $\mathrm{Li}<\mathrm{Na}<\mathrm{K}$ and the order of release $\mathrm{Li}>\mathrm{Na}>\mathrm{K}$.

The relative symmetry values of mono- and divalent cations are shown in Table 5 and Figure 10. These results indicate that the humus is intermediate between Putnam clay and bentonite with respect to its colloidal properties. The $\mathrm{Mg}$ has a high energy of adsorption and low flocculating effect is difficult to explain except on

Table 5.-Relative Adsorption of Cations by Colloidal Humus and Colloidal Alumino-Silicates at Symmetry Conceintratton.

\begin{tabular}{|c|c|c|c|c|}
\hline Added electrolyte & $\begin{array}{c}\text { H- } \\
\text { Permutite* }\end{array}$ & $\begin{array}{c}\mathrm{H}- \\
\text { Putnam clay* }\end{array}$ & $\underset{\text { Humus }}{\mathrm{H}-}$ & $\begin{array}{c}\mathrm{H}- \\
\text { Bentonite* }\end{array}$ \\
\hline 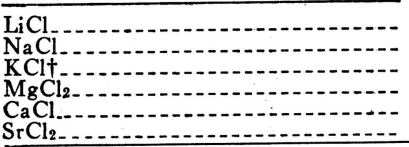 & $\begin{array}{r}15 \\
40 \\
100 \\
-- \\
-- \\
--\end{array}$ & $\begin{array}{r}55 \\
50 \\
100 \\
66 \\
133 \\
145 \\
\end{array}$ & $\begin{array}{r}83 \\
85 \\
100 \\
91 \\
94 \\
81 \\
\end{array}$ & $\begin{array}{r}97 \\
82 \\
100 \\
-- \\
-- \\
\end{array}$ \\
\hline
\end{tabular}

*Calculated from data of H. Jenny; divalent ions of Putnam clay from J. Gieseking and H. Jenny. $\dagger$ For monovalent ions $\mathrm{K}=100$, divalent ions $\mathrm{Ba}=100$. 


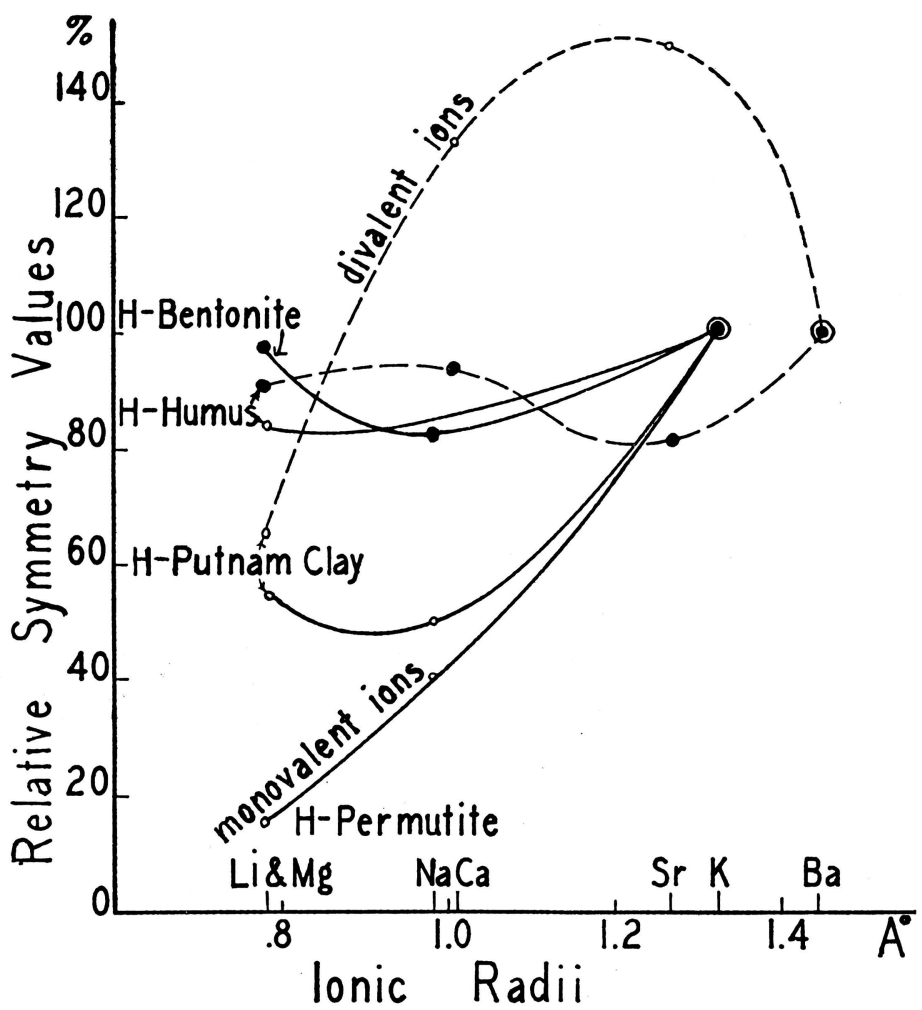

Fig. 10.-Relative symmetry values of various colloids as a function of ionic radii.

the basis of a dispersion effect. The $\mathrm{Mg}$ ion is the same size as the $\mathrm{Li}$ ion and it would be expected to be more highly hydrated than the $\mathrm{Ca}$ or $\mathrm{Ba}$ ions. It is probable that in spite of its divalency, $\mathrm{Mg}$ causes dispersion due to its hydration.

\section{Reversibility}

Bontarie and Thevenet $^{3}$ found that dried humus could not be resuspended in water. They also made the observation that colloidal H-humus undergoes a change with time which is magnified by heat. This is confirmed by the observation that when H-humus systems are allowed to stand without disturbing for relatively long periods, they require a large amount of mechanical energy, in the form of agitation, to obtain complete dispersion. Small compact aggregates were noted that were highly resistant to dispersion by shaking. This was not noted in the $\mathrm{Ca}$ - or Ba-humus systems which were more flocculated than the H-systems. The results of reversibility are plotted in Figure 11. It was expected that the $\mathrm{K}$-humus would quickly redisperse and that the order of reversibility would be $\mathrm{K}>\mathrm{H}>\mathrm{Ca}$. It is of great inter- 


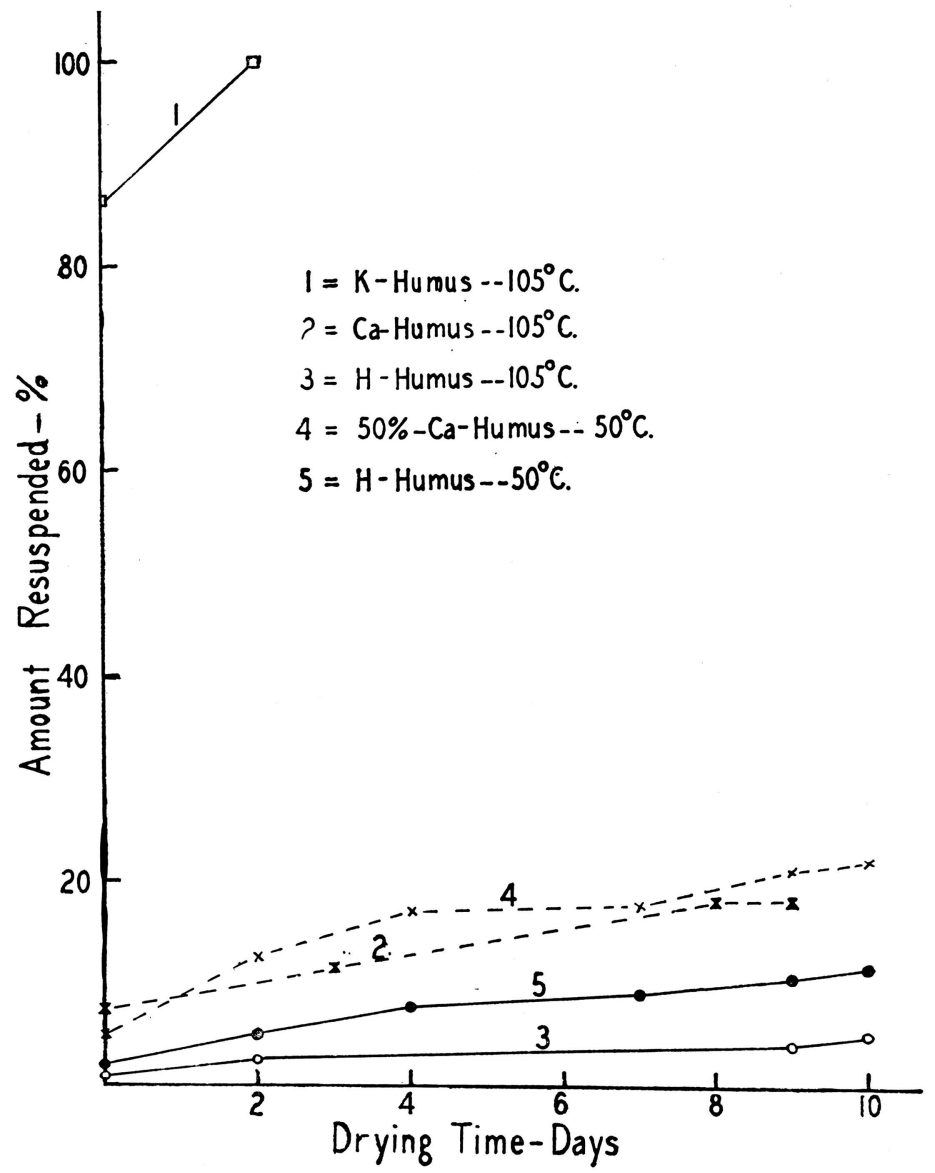

Fig. 11.-Reversibility of colloidal humus systems after desiccation.

est to note that $\mathrm{Ca}$-humus is more easily reversible than $\mathrm{H}$-humus. It is interesting to note that the effect of the temperature of dehydration is not as pronounced with the Ca-systems as with the H-humates. The reversibility of $\mathrm{H}$-humate increases as the temperature of dehydration decreases. However, only about $11 \%$ of the colloidal humus, dried at $50^{\circ} \mathrm{C}$., is reversible during a ten-day period. A $50 \%$ Ca-saturated humus is about $22 \%$ reversible. The high resistance to dispersion of H-humus after drying and the alteration of the system with standing suggests the orientation of $\mathrm{H}$-humus particles with respect to one another. The exact order of orientation is not known. 


\section{DISCUSSION OF RESULTS}

Bradfield ${ }^{4}$ found that the H-Putnam clay colloid migrated towards the anode with a velocity of $21.5 \times 10^{-5} \mathrm{~cm}$. per second per unit gradient. Comparing this with the velocity of the H-humus we find that according to Table 2, H-humus has about half the potential of H-clay. Another comparison that is noteworthy is that of the migration velocities and the degree of flocculation of the saturated systems. Figures 4 to 10 , inclusive, show that the order of increasing flocculations is: $\mathrm{Li}=\mathrm{Na}=$ $\mathrm{K}<\mathrm{H}<\mathrm{Ca}<\mathrm{Ba}$. With the exception of the slight decrease in the migration velocity of $\mathrm{K}$-humus, this is the order of decreasing migration velocity.

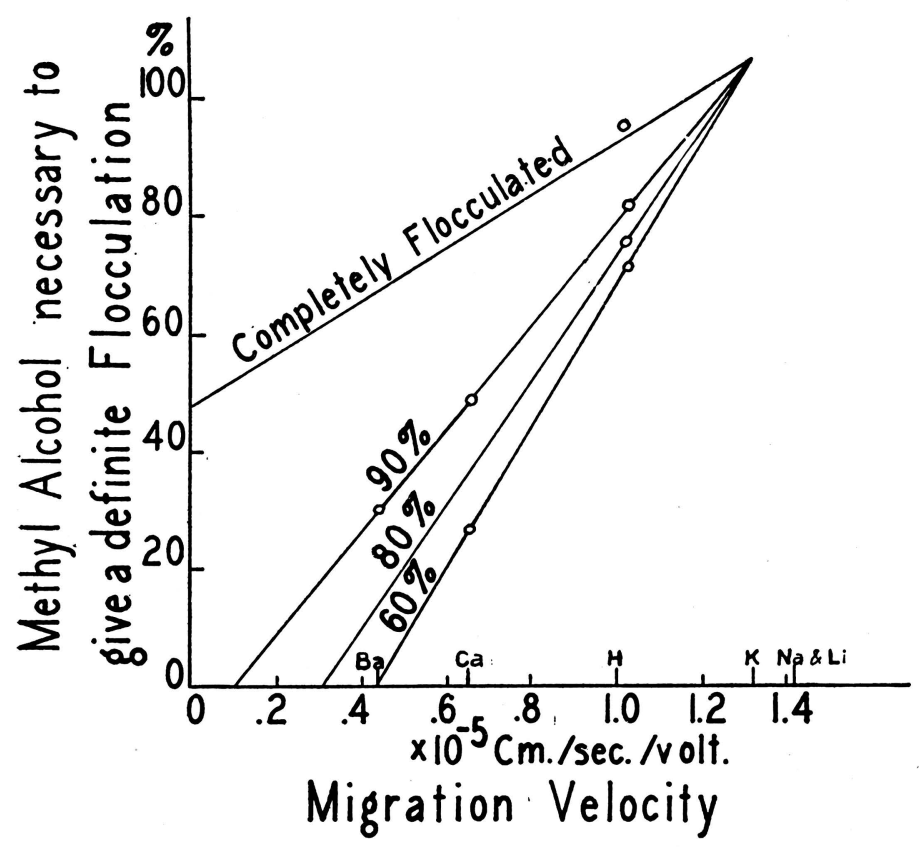

Fig. 12.- Relation between hydration and migration velocity of colloidal humus systems.

The stability of the humus system appears to be largely a function of the hydration. If the percentage of methyl alcohol that is required to produce a definite flocculation is used as an index of the hydration, Figure 12 shows that the migration velocity has to be reduced to a value of less than $11.6 \times 10^{-5} \mathrm{~cm}$. per second per volt gradient before flocculation can be effected. This point may be termed the critical potential of a dehydrated system. Humus systems that have a migra- 
tion velocity greater than $11.6 \times 10^{-5} \mathrm{~cm}$. per second per volt gradient can not be flocculated by dehydration; those with a lower charge can be flocculated. As the charge of the system is reduced, the percentage alcohol necessary to produce flocculation is lowered, indicating that below this critical potential the stability of the colloidal humus is largely due to the degree of hydration. It is for this reason that monovalent ions have so little flocculating effect on the various humus systems containing exchangeable cations. The monovalent ions, because of their high ionic hydration and low charge, are unable to dehydrate the humus systems or to reduce the charge sufficiently to produce flocculation.

Further indication of the hydration of colloidal humus systems is given by the correlation of the relative symmetry values with those values available for the colloidal alumino-silicates, as shown in Figure 10. The similarity of the relative symmetry values of colloidal humus and bentonite for monovalent ions indicates that this humus is a hydrated suspensoid. The high hydration of the colloidal humus may explain the low migration velocities with respect to the Putnam clay system. It can be seen that if the humus particles were surrounded by a large water hull, as in the monovalent systems, or had a large amount of occluded water in the floccule, their ability to migrate in an electrical field would be slowed down considerably. Reasoning this same way, it might be expected that the $\mathrm{H}$-humus has as much as twice the hydration of Putnam clay. Actually, as will be shown, hydration calculations show the humus to be one and one-half times more hydrated.

Lutz $^{10}$ found that the $\mathrm{Na}$-bentonite was about six times more highly hydrated than the Na-Putnam as calculated by the Mark and Meyer equation from viscosity measurements. Using the same equation, the calculated hydration of the Na-humus is found to be one and one-half times that of the Na-Putnam. The order of the hydration of the monovalent humus systems is $\mathrm{Li}>\mathrm{Na}>\dot{\mathrm{K}}$, which is the same order as found by Lutz with bentonites. If the relative hydration of various colloidal alumino-silicates and humus are plotted as a function of the ionic size, it will be seen from Figure 13 that the lyotropic series is more pronounced with the increasing hydration of the colloid. The hydration results lend support to the conception that the colloidal humus is a highly hydrated suspensoid and confirms the opinion of Bontarie and Thevenet ${ }^{3}$ that humus is intermediate between a true suspensoid and true emulsoid.

The influence of the various cations on the flocculation of colloidal humus systems brings to light some interesting facts. The 


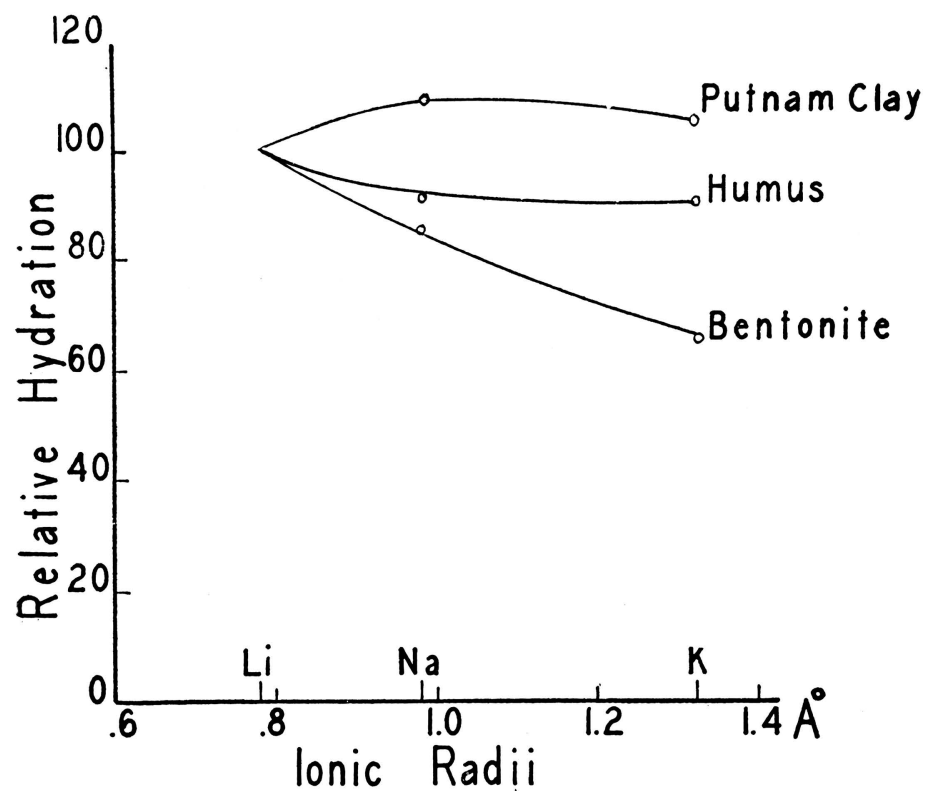
silicates.

results indicate that the $\mathrm{H}$ ion is a more powerful flocculating agent than the $\mathrm{Ba}$ or $\mathrm{Ca}$ ions. This is contrary to the usual valence effects and confirms once more the fact that the $\mathrm{H}$ ion acts more like a divalent ion in surface reactions than as a monovalent ion. As pointed out before, $\mathrm{Sr}$ is out of its ionic order in the effectiveness of flocculation. It is difficult to assign a satisfactory explanation to the observed behavior of this ion. The fact that it is consistently out of order with respect to flocculation and that it falls low in the order of energy of adsorption warrants. further investigation relative to its behavior on colloidal humates.

The low flocculating power of the $\mathrm{Mg}$ ion on humates is important from a soil morphological standpoint. Various investigators have reported data that indicate the formation of solonetz soils in the presence of $\mathrm{Mg}$ as well as $\mathrm{Na}$ ions. Rost ${ }^{14}$, investigating the solonetz soils of Minnesota, reports a high percentage of exchangeable $\mathrm{Mg}$ in the $\mathrm{B}$ horizon of these soils. Exchangeable $\mathrm{Mg}$ has been shown to have a very limited effect on the peptization of the inorganic fraction, consequently, there is considerable question concerning the influence of the 
$\mathrm{Mg}$ ions on the morphology of these soils. Figures 3, 4, and 5 indicate that in presence of alkali cations less than 50 per cent flocculation occurs on addition of $\mathrm{Mg}$ at four times the symmetry concentration. In the presence of $\mathrm{Ca}$, (Figure 7) $\mathrm{Mg}$ behaves more like a monovalent cation in concentrations up to that required to saturate the complex. The relatively high energy of adsorption and low flocculating power of $\mathrm{Mg}$ on colloidal humates is offered as a possible explanation of the mobility of the organic matter in $\mathrm{Mg}$-solonetz.

The action of the Th ion is in keeping with results reported by Freundlich ${ }^{6}$. The flocculation and subsequent redispersion with a reversal of the charge was noted with oil drops (page 418), and with a gold sol (page 431). All of the colloidal humus systems studied show this phenomenon of redispersion (Fig. 10). The addition of 75 m.e. $\mathrm{ThCl}_{4}$ per $100 \mathrm{gms}$. of humus to a $0.42 \% \mathrm{Li}$-saturated sol caused a definite resuspension and a reversal of charge. The $\mathrm{Li}$-sol to which 25 m.e. $\mathrm{ThCl}_{4}$ per $100 \mathrm{gms}$. was added was completely flocculated; the sol was slightly positive in charge.

The organic matter content of prairie, chernozem, and chestnut soils is often explained in the textbook as resulting from the stabilization of the organic matter by the $\mathrm{Ca}$ present. The results on the reversibility of $\mathrm{Ca}$ - and $\mathrm{H}$-humus do not substantiate this viewpoint. At the end of 10 days there was four times as much Ca-humus resuspended as there was H-humus. This would tend to support the contention that acid soils would stabilize the organic matter more than neutral alkaline soils.

The climate under which the aforementioned soils are formed is semi-humid to semi-arid. Under these conditions there is ample moisture for plant growth, but there is generally an extended hot, dry period during the summer months. The length of this period and the magnitude of the temperature are ample for the desiccation of the humus formed and to cause its stabilization. The humus formed under these conditions will be high in bases and, with the event of rain on the desiccated humus, part of it will become resuspended and move down into the soil with percolating waters. This process of illuviation would cause a distribution of organic matter through the upper solum. Another factor in the accumulation of humus throughout the upper solum is the production and subsequent decomposition of an abundant supply of roots. Undoubtedly, an important function of the $\mathrm{Ca}$ in these soils is to aid in the production of a more luxuriant growth which in turn supplies an increased amount of organic matter to the soil. 
It is of considerable interest to make a comparison of the behavior of colloidal humus and clays. Baver ${ }^{2}$ found that by adding symmetry concentrations of $\mathrm{Ca}$ and $\mathrm{Mg}$ as the hydroxide to H-Putnam clay that complete flocculation resulted. Figure 6, shows that H-humus requires one symmetry of $\mathrm{CaCl}_{2}$ and two symmetry concentration of $\mathrm{MgCl}_{2}$ to produce complete flocculation. The potential of the H-Putnam is twice that of the H-humus; hydration calculations from viscosity determinations show that the H-humus is two and one-half times as highly hydrated as the H-Putnam clay. Lutz ${ }^{10}$ reported that a 2 per cent $\mathrm{H}$ Putnam flocculated in about 3 days. Figure 6 shows that a 0.42 per cent H-humus as prepared is about 40 per cent flocculated. Lutz. found the relative viscosity of a 2 per cent H-Putnam to be 1.21 as. compared to 1.10 for a 0.42 per cent $\mathrm{H}$-humus.

Baver $^{2}$ reports that the migration velocity of Ca-Putnam is less than H-Putnam which is in accord with the results of this investigation. The relative viscosity of the Ca-Putnam as reported by Lutz is 1.19' and the water of hydration is $3.19 \mathrm{cc}$. per gram. The Ca-humus has a relative viscosity of 1.11 and a hydration of $10.14 \mathrm{cc}$. per gram. This. indicates that the volume of the Ca-humus floccule is about 3 times. that of the Ca-Putnam clay.

The similarity of the energy of release and adsorption of $\mathrm{Ca}$ with respect to the $\mathrm{H}$ of the Putnam clay and humus suggests that the distribution of exchangeable calcium in a soil between the organic and inorganic colloids will be in proportion to the concentration of the two systems. This, of course, is with the assumption that there is no mutual adsorption of the organic and inorganic systems. It would be expected that any reduction in the total exchange capacity of a system due to the adsorption of organic matter on clay would alter the distribution of cations in favor of the organic matter.

The results reported in this paper indicate that the colloidal behavior of soil organic matter is similar to that of the inorganic fraction. The high degree of hydration of humus fraction is responsible for the variations found.

Inasmuch as the effects of exchangeable $\mathrm{H}$ and $\mathrm{Ca}$ ions on the colloidal properties of both humus and clay are quite similar, considerable study is needed on the indirect influence of calcium on soil structure in order to clarify many of the conflicting concepts of the importance of calcium in soil morphology. 


\section{SUMMARY AND CONCLUSIONS}

A study of the colloidal nature of soil organic matter has produced the following results:

1. The potential of colloidal humus, as measured by migration velocity, is about one-half that of colloidal Putnam clay. The migration velocity of humus saturated with various cations decreased in the order: $\mathrm{Li}=\mathrm{Na}>\mathrm{K}>\mathrm{H}>\mathrm{Ca}>\mathrm{Ba}$.

2. The viscosity of the various systems followed the order: $\mathrm{Ba}>$ $\mathrm{Ca}>\mathrm{H}>\mathrm{Na}>\mathrm{Li}>\mathrm{K}$. The higher viscosity of the $\mathrm{Ba}-, \mathrm{Ca}-$, and $\mathrm{H}$-systems was due to flocculation effects.

3. Humus systems that were saturated with $\mathrm{Li}, \mathrm{Na}$, and $\mathrm{K}$ ions were completely dispersed and flocculated with difficulty. More than twice the symmetry concentration of $\mathrm{HCl}, \mathrm{BaCl}_{2}$, and $\mathrm{CaCl}_{2}$ were required to produce significant flocculation. They could not be flocculated by dehydration with methyl alcohol.

4. At symmetry concentration the flocculating power of various cations followed the order: $\mathrm{La}>\mathrm{H}>\mathrm{Ba}>\mathrm{Ca}>\mathrm{Sr}>\mathrm{Mg}>\mathrm{K}>$ $\mathrm{Na}=\mathrm{Li}$. The $\mathrm{Mg}$ ion acted like a monovalent cation relative to flocculation.

5. Addition of tetravalent thorium ions to H-humate in low concentrations caused flocculation of the humus. In higher concentrations there was a redispersion due to a reversal of charge.

6. The energy of adsorption and release of the several cations studied was of the same order of magnitude as in colloidal Putnam clay. The adsorption of these cations at symmetry concentration on $\mathrm{H}$-humate was as follows:

$\mathrm{Th}^{++++}>\mathrm{La}^{+++}>\mathrm{Ba}^{++}>\mathrm{Mg}^{++}>\mathrm{Sr}^{++}>\mathrm{K}^{+}>\mathrm{Na}^{+}>\mathrm{Li}^{+}$

1. The reversibility of dehydrated $\mathrm{Ca}$ - and H-humate is very low. The percentage reversibility of Ca-humus was four times that of H-humus in a ten-day period. H-humus was completely reversible in two days.

These results make possible the following conclusions concerning the colloidal properties of soil organic matter.

1. Colloidal humus behaves like a highly hydrated suspensoid. Hydration is of major importance in the stability of divalent humus sols. The high hydration of humus places it between 
colloidal clay and bentonite with respect to most of its properties.

2. The relatively high energy of adsorption and low flocculating power of the $\mathrm{Mg}$ ion with respect to organic matter suggests a possible explanation of the formation of $\mathrm{Mg}$ solonetz soils. Mg-humates would be mobile, especially in the presence of small amounts of alkali cations.

3. The higher reversibility of dehydrated Ca-humus as compared with $\mathrm{H}$-humus points out the possibility of the migration of organic matter to relatively great depths in pedocal soils. Since $\mathrm{Ca}$ - and $\mathrm{H}$-saturated humus have similar properties relative to flocculation and since $\mathrm{Ca}$-humates are more reversible in water than the corresponding H-systems, it would seem that the importance of calcium in the nutrition of plants in the production of vegetation is a more significant factor in organic matter accumulation than has hitherto been recognized.

4. The fact that the properties of the $\mathrm{Ca}$ - and H-saturated systems of colloidal clays as well as colloidal humus are not significantly different indicates quite strongly that the content of organic matter in soils is more important for stable structure formation than its percentage saturation with calcium. 


\section{BIBLIOGRAPHY}

1. Baver, L. D. The Effect of Organic Matter Upon Several Physical Properties of Soils. Jour. Am. Soc. Agron., 22, (1930), pp. 703-708.

2. Baver, L. D. The Effect of the Amount and Nature of Exchangeable Cation on the Structure of a Colloidal Clay. Mo. Exp. Sta. Res. Bul. 129 (1929).

3. Bontarie, A. and Thevenet, S. Recherches Physico-Chimiques sur les Colloides Humiques. Ann. Agron., 7 (1937), pp. 18-32.

4. Bradfield, R. The Chemical Nature of Colloidal Clay. Mo. Exp. Sta. Res. Bul., 60 (1923).

5. Bradfield, R. and Allison, W. H. Criteria of Base Saturation of Soils. Trans. Sec. Comm. and Alk. Subcomm. Int. Soc. Soil Sci., Vol. A (1933), pp. 63-79.

6. Freundlich, H. Colloid and Capillary Chemistry. Trans. by H. S. Hatfield, Ed. 3, N. Y., E. P. Dutton, 1923.

7. Gieseking, J. E. and Jenny, H. Behavior of Polyvalent Cations in Base Exchange. Soil Sci. 42 (1936), pp. 273-280.

8. Hissink, D. J. The Relation Between the Values, $p H, V$ and $S$ (Humus) of Some Humus Soils. S (Humus) and $V$ of these Soils with $p H-7$. The Equivalent Weight of the Humus Substance. Proc. Sec. Comm. Int. Soc. Soil Sci., Vol. A (1926), pp. 198-204.

9. Jenny, H. Studies on the Mechanism of Ionic Exchange in Colloidal Alumino-silicates. Jour. Phsy. Chem. 36 (1932), pp. 2217-2258.

10. Lutz, J. F. The Physico-Chemical Properties of Soils Affecting Soil Erosion. Mo. Exp. Sta. Res. Bul., 212, (1934).

11. McGeorge, W. T. Organic Compounds Associated with Base Exchange Reactions in Soils. Ariz. Sta. Tech. Bul., 31 (1931), pp. 215-251.

12. Odén, S. Die Huminsaüren. Kolloidchem. Beihefte. 11 (1919), pp. 76-260.

13. Powers, W. L. Characteristics of Dispersible Organic Colloids in Peat. Jour. Agr. Res. 44 (1932), pp. 97-111.

14. Rost, C. O. Characteristics of Some Morphological Solonetz Soils of Minnesota. Jour. Am. Soc. Agron. 28 (1936), pp. 92-105.

15. Scheele, W. and Rowe, W. Über Humussaüren. III. Über eine Methode zur Quantitativen Bestimmung von Humussaüren in Extrakton durch Konduktometrische Titration. Kolloid Zeit. 75 (1936), pp. 73-79.

16. Waksman, S. A. The Origin and Nature of Soil Organic Matter of Soil "Humus." II. Method of Determining Humus in the Soil. Soil Sci 22 (1926), pp. 221-232. 

Unvessir of Missoun - coumen
VET PER
ISNB $880736256251-275,1937 / 38$

030-000890913

384045

630.274

M693a

\#251-275

$1937-38$

Lib.

Vet.

Vet.

630.274

ش693a

\# 251-275 
University Libraries

University of Missouri

Digitization Information Page

Local identifier

Source information

\section{Format}

Content type

Source ID

Notes

Capture information

Date captured

Scanner manufacturer

Scanner model

Scanning system software

Optical resolution

Color settings

File types

Derivatives - Access copy

Compression

Editing software

Resolution

Color

File types

Notes
ResearchBulletin267

Book

Text

030-000890913
June 2019

Fujitsu

fi-7460

ScandAll Pro v. 2.1.5 Premium

600 dpi

24 bit color

tiff
Tiff: LZW compression

Adobe Photoshop CC

600 dpi

grayscale

tiff

Image cropped, straightened, brightened 